\title{
Shock wave lithotripsy, for the treatment of kidney stones, results in changes to routine blood tests and novel biomarkers: a prospective clinical pilot-study
}

Stephen F. Hughes ${ }^{1,2^{*}} \mathbb{C}$, Nathan Jones ${ }^{3,4}$, Samantha J. Thomas-Wright ${ }^{2,5}$, Joseph Banwell ${ }^{2,5}$, Alyson J. Moyes $2,3,6$ and lqbal Shergill ${ }^{1,2,7}$

\begin{abstract}
Background: The number of patients undergoing shock wave lithotripsy (SWL) for kidney stones is increasing annually, and as such the development of post-operative complications, such as haematuria and acute kidney injury (AKI) following SWL, is likely to increase. The aim of the study was to evaluate changes in routine blood and novel biomarkers following SWL, for the treatment of kidney stones.

Methods: Twelve patients undergoing SWL for solitary unilateral kidney stones were recruited. From patients (8 males and 4 females) aged between 31 and 72 years (median 43 years), venous blood samples were collected preoperatively (baseline), at 30, 120 and 240 min post-operatively. Routine blood tests were performed using a Sysmex XE-5000, and Beckman Coulter AU5800 and AU680 analysers. NGAL, IL-18, IL-6, TNF-a, IL-10 and IL-8 concentrations were determined using commercially available ELISA kits.

Results: Significant $(p \leq 0.05)$ changes were observed in several blood parameters following SWL. NGAL concentration significantly increased, with values peaking at 30 min post-treatment $(p=0.033)$. Although IL-18 concentration increased, these changes were not significant $(p=0.116)$. IL-6 revealed a statistically significant rise from pre-operative up to $4 \mathrm{~h}$ post-operatively $(p<0.001)$, whilst TNF-a significantly increased, peaking at 30 min post-SWL $(p=0.05)$.

There were no significant changes to IL-10 and IL-8 concentrations post-SWL $(p>0.05)$.

Conclusions: Changes to routine blood tests and specific biomarkers, in the future, may be more useful for clinicians. In turn, identification of a panel of biomarkers could provide valuable data on "normal" physiological response after lithotripsy. Ultimately, studies could be expanded to identify or predict those patients at increased risk of developing post-operative complications, such as acute kidney injury or. These studies, however, need validating involving larger cohorts.
\end{abstract}

Keywords: Shock wave lithotripsy (SWL), Biomarkers, Kidney stones, Inflammation, Routine blood tests, Acute kidney injury (AKI)

*Correspondence: Stephen.hughes6@wales.nhs.uk

${ }^{1}$ North Wales Clinical Research Centre, Betsi Cadwaladr University Health Board (BCUHB) Wrexham Maelor Hospital, Wrexham, Wales, UK

Full list of author information is available at the end of the article

\section{Background}

Kidney stones are becoming an increasing clinical and economic burden on global health services [1]. Shock wave lithotripsy (SWL) allows a non-invasive treatment of kidney stones smaller than $2 \mathrm{~cm}$ [2]. Recent evidence suggests that SWL treatments are being used more

c) The Author(s) 2020. This article is licensed under a Creative Commons Attribution 4.0 International License, which permits use, sharing, adaptation, distribution and reproduction in any medium or format, as long as you give appropriate credit to the original author(s) and the source, provide a link to the Creative Commons licence, and indicate if changes were made. The images or other third party material in this article are included in the article's Creative Commons licence, unless indicated otherwise in a credit line to the material. If material is not included in the article's Creative Commons licence and your intended use is not permitted by statutory regulation or exceeds the permitted use, you will need to obtain permission directly from the copyright holder. To view a copy of this licence, visit http://creativeco mmons.org/licenses/by/4.0/. The Creative Commons Public Domain Dedication waiver (http://creativecommons.org/publicdomain/ zero/1.0/) applies to the data made available in this article, unless otherwise stated in a credit line to the data. 
frequently, as there has been a $2 / 3$ increase in the prevalence of kidney stones in the UK over a 10 -year period [3].

Despite the use of radiological imaging to accurately direct shock waves to the location of the kidney stone, there is still a risk of localised complications associated with SWL [4]. The most common SWL-associated injury is primary vascular haemorrhage [5]. Originally, it was thought that the prevalence of renal haematoma in patients post-operatively was $<1 \%$, however, it was later discovered that $29 \%$ of patients developed haematomas post-SWL $[5,6]$. Renal trauma also results in an inflammatory response that initiates tissue remodelling and can result in the production of scar tissue [7]. Research has shown that dose-dependant renal fibrosis occurred in canine subjects undergoing SWL [8]. Fibrosis of renal tissue can result in a partial or complete loss of function to the affected area. One study reports that $\sim 10 \%$ of SWL patient can experience a urinary tract infection after treatment [9]. The overall complication rate, according to CROES URS study, was up to $25 \%$, which included haemorrhage, pyrexia, urine infection (UTI), acute kidney injury (AKI) and sepsis as the most common post-operative complications [10]. However, other potentially devastating injuries following SWL have been reported, including acute pancreatitis, splenic rupture, bowel injury with perforation, myocardial infarction, and rupture of abdominal aortic aneurysms [11-14]. In addition, it is expected that there will be a greater incidence, more recurrent episodes and overall higher number of patients having SWL. Subsequently, the complication rate is likely to increase, especially with an aging society. As such, it may be advantageous to identify patients who are at increased risk of developing complications following SWL.

Current practice provides little, if any, knowledge regarding identifying, or predicting, those patients at increased chance of complications. Novel biological parameters have the potential to identify complications such as bleeding, acute kidney injury and infection, which may arise following SWL. Importantly, to date, there is limited research evaluating the pathophysiological effects of SWL on clinical outcome measures. Crucially, at present, there are minimal studies that have reported the impact of SWL on novel biomarkers such as NGAL, IL-18, IL-6, TNF- $\alpha$, IL-10 and IL-8.

Previously, our group have published outcomes of haemostatic function following SWL and other operative surgeries, and this may provide a good foundation to undertake larger studies that may ultimately determine which patients are at increased risk of haemorrhage following surgeries [15-18]. Moyes et al. [19] documented that changes to several biochemical and haematological parameters occur following flexible ureteroscopy (FURS), for the removal of kidney stones. Specifically, FURS is an invasive procedure employed for the treatment of stone disease. During this study, 4 patients from 40 developed post-operative complications, which resulted in significant changes to several of the routine biochemical and haematological blood tests. The information provided in this paper, in turn, highlights the need and the importance to undertake further research in this area, and to fully understand the 'normal' response to these treatments.

Neutrophil gelatinase-associated lipocalin (NGAL) is a protein that is bound to matrix metalloproteinase- 9 (MMP-9) in neutrophils [20]. NGAL is generally found in low concentrations in human tissue, but is significantly increased in cases of trauma to kidney, colon, liver and lung tissue [21]. Originally identified as a component of neutrophil granules, it has since been found to be produced by tissues undergoing inflammation [22]. It has been shown in patients with chronic kidney disease (CKD) that NGAL concentrations correlate with the severity of renal impairment; however, it has been found that NGAL concentrations are much higher in patients with AKI compared with CKD [20,21]. The upregulation of NGAL during AKI, may therefore provide a specific novel biomarker following SWL, which may help predict or identify an abnormal response to treatment, such as AKI.

Cytokine-mediated inflammation has been implicated in the pathogenesis of AKI and chronic kidney CKD, where endothelial and tissue injuries are associated with the release of specific mediators that may initiate the inflammatory cascade [23, 24]. Interleukin 18 (IL-18) is a pro-inflammatory cytokine, which is upregulated during an inflammatory response. The majority of IL-18 expressed is from activated macrophages; however, IL-18 has also been shown to be expressed in renal tubular epithelial cells [25]. Urine IL-18 concentrations have been found to be significantly raised in patients with AKI compared to those with urinary tract infection, chronic renal insufficiency and nephrotic syndrome [26]. This demonstrates that IL-18 is upregulated in cases of AKI rather than CKD, making it a possible biomarker for the identification of acute injuries following SWL.

Interleukin-6 (IL 6) is a typical example of a multifunctional cytokine involved in the regulation of the immune response, haematopoiesis, and inflammation. Raised serum levels of IL-6 have been associated with sepsis in AKI patients [23, 24]. One of the principal acute-phase cytokines produced by monocytes and macrophages in response to infection is tumour necrosis factor-alpha (TNF- $\alpha$ ). TNF- $\alpha$ has a complex and extensive repertoire of functions within the inflammatory cascade system 
[27]. Increased levels of TNF- $\alpha$ are thought to potentially prime and therefore elicit a more rapid and prominent response from neutrophils during the inflammatory process and may therefore be appreciated to be a noble biomarker for evaluating sustained inflammation or predicting complications [28].

Predominantly, interleukin-8 (IL-8) is a cytokine, comes from leukocytes and many types of cellular tissues. Neutrophils are a major specific target for IL-8 action. IL-8 is routinely being used as a marker for various clinical conditions and is associated with chronic diseases, infections and inflammation [29, 30]. IL-8 has also been reported to be detected in the urine of patients with several inflammatory renal disorders including pyelonephritis, haemolytic uraemic syndrome, graft rejection and various forms of glomerulonephritis [31].

IL-10 levels appear to have been overlooked in urology studies, with information regarding this biomarker and its relation to kidney damage being vague. IL-10 has been reported to play an integral role with respect to infection, as well as inflammation, due to its anti-inflammatory effect [30]. However, as previously mentioned this cytokine is also affected by many other factors. Serum, peritoneal fluid and saliva levels of IL-10 are known to be elevated in conditions such as infections, melanoma, tumours, and autoimmune diseases [32, 33].

As highlighted above, studies involving cytokines in various clinical settings have been well documented. However, with respect to urology, there are limited studies evaluating the role of cytokines following kidney stone treatment and are therefore worthy of investigation.

We aimed to evaluate changes in routine haematological and biochemical blood tests, including novel biological parameters, namely NGAL, IL- 18 , IL-6, TNF- $\alpha$, IL-10 and IL-8. This should allow us to understand better, the postoperative biological pathway following SWL, in kidney stone management. This pilot-study has the potential to add a significant body of work to the literature, as well as providing the biological basis for future multi-centre studies.

\section{Methods}

\section{Subject volunteers and shock wave lithotripsy (SWL)}

Following ethical approval (Integrated Research Application System REC 4:12/WA0117), and written informed consent, we recruited 12 patients who underwent SWL for kidney stone treatment. Of these, 8 were male, and the remaining 4 were female. The median age was 43 years (range 31 to 72). Using standard hospital protocol, SWL therapy was delivered with Wolf P3000 lithotripter, incorporating triple focus technology, and ultrasound/ fluoroscopic imaging was used for localisation.

\section{Blood samples}

Baseline (control) samples of venous blood were taken before SWL, using a cannula inserted into the antecubital fossa for each patient. Subsequent sampling was undertaken at 30, 120 and 240 min post-operatively. Trained healthcare staff were present throughout the study period ensuring that blood samples were collected at the specific time-points. Vacutainers containing dipotassium ethylene diamine tetra-acetic acid (EDTA) were used for sample collection. Plasma was obtained by centrifugation at $1000 \mathrm{~g}$ for $15 \mathrm{~min}$. Plasma was removed from the vacutainer and stored in aliquot tubes at $-80{ }^{\circ} \mathrm{C}$ until required for analysis.

An $87.5 \%$ compliance was obtained regarding blood sample collection. Participants 2,7 and 10 (12.5\% of the total participants) were unable to provide blood samples at 120 and $240 \mathrm{~min}$ post-operatively due to difficulty (i.e. poor veins) with the venesection.

\section{Measurement of haematological and biochemical parameters}

Full blood count $(\mathrm{FBC})$ was undertaken via a Sysmex XE-5000 automated cell counter, and biochemistry tests undertaken using the Beckman Coulter AU5800 and AU680 analysers.

\section{Measurement of NGAL, IL-18, IL-6, TNF- $a$, L-10 and IL-8 concentrations}

Commercially available Human Quantikine ${ }^{\circledR}$ ELISA kits for NGAL, IL-18, IL-6, TNF- $\alpha$, IL-10 and IL- 8 were purchased from $R \& D$ Systems ${ }^{\circledR}$ catalogue numbers: DLCN20, 7620, D6050, DTA00C, D1000B and D8000C, respectively. All assays were run as per manufacturer's instructions, in duplicate, with sample analysis being undertaken when enough patients were recruited on to the study to run a single 96 -well assay plate $(n=3$ plates per biomarker). Intra-assay \% coefficient of variability $(\mathrm{CV})$ levels are reported, with a $\mathrm{CV}$ of $<10 \%$ being acceptable, ensuring assay precision and high performance. Biomarker assay specifications are illustrated in Table 1.

\section{Statistical analysis}

Statistical analysis was carried out using SPSS (latest version). Initial testing for normality was carried out, and where data were parametric, repeated measures analysis of variance (ANOVA) between samples test was employed, adopting a $5 \%$ level of significance. Post hoc testing was conducted using the Bonferroni test for pairwise comparisons between means. Data that did not comply with normality were analysed using the Friedman test. Where the Friedman test resulted in statistical 
Table 1 Biomarker assay specifications

\begin{tabular}{llll}
\hline Biomarker ELISA assay & Assay range (limits of detection) & Sensitivity & Specificity \\
\hline NGAL & $0.2-10 \mathrm{ng} / \mathrm{ml}$ & $0.04 \mathrm{ng} / \mathrm{ml}$ & Natural and recombinant human lipocalin-2 \\
IL-18 & $26.6-1700 \mathrm{pg} / \mathrm{ml}$ & $7.52 \mathrm{pg} / \mathrm{ml}$ & Natural and recombinant human total IL-18 \\
IL-6 & $3.1-300 \mathrm{pg} / \mathrm{ml}$ & $0.7 \mathrm{pg} / \mathrm{ml}$ & Natural and recombinant human IL-6 \\
TNF-a & $15.6-1000 \mathrm{pg} / \mathrm{ml}$ & $5.5 \mathrm{pg} / \mathrm{ml}$ & Natural and recombinant human TNF-alpha \\
IL-10 & $7.8-500 \mathrm{pg} / \mathrm{ml}$ & $3.9 \mathrm{pg} / \mathrm{ml}$ & Natural and recombinant human IL-10 \\
IL-8 & $31.2-2000 \mathrm{pg} / \mathrm{ml}$ & $7.5 \mathrm{pg} / \mathrm{ml}$ & Natural and recombinant human IL-8 \\
\hline
\end{tabular}

significance, subsequent tests were performed using the Wilcoxon test. Statistical significance was accepted when $p \leq 0.05$. All parametric data are presented as mean \pm standard deviation (SD), whilst non-parametric results are presented as median \pm interquartile range (IQR), reporting the lower (25 percentile) and upper (75 percentile) bound IQRs.

\section{Results}

\section{Haematological blood results}

Haematological changes following SWL are presented in Table 2. The following biomarkers exhibited statistically significant decreases: basophils $(p=0.041)$, haemoglobin $(p=0.002)$, red blood cells $(p=0.001)$, and packed cell volume $(p=0.002)$. Furthermore, significant increases were seen in white blood cell (WBC) levels $(p=0.009)$, neutrophils $(p=0.017)$, monocytes $(p=0.003)$ and mean corpuscular haemoglobin $(p=0.047)$. No changes were reported in lymphocytes, eosinophils, mean cell volume, and mean corpuscular haemoglobin concentration $(p>0.05)$.

\section{Biochemistry blood results}

Biochemical changes following SWL are presented in Table 3. The following exhibited statistically significant decreases: total protein $(p=<0.001)$, albumin $(p=<0.001)$, globulin $(p=0.006)$, alkaline phosphatase $(p=0.018)$ and sodium $(p=0.01)$. Furthermore, significant increases were seen in alkaline transaminase $(p=0.01)$. No changes were reported in CRP, total bilirubin, urea, creatinine, and potassium $(p>0.05)$.

\section{Novel biomarkers blood results \\ NGAL}

Plasma NGAL concentration increased from baseline (pre-operative) $(127.3 \pm 87.4 / 166.8)$ and peaked at $30 \mathrm{~min}$

Table 2 Haematological changes following SWL $(n=12)$

\begin{tabular}{|c|c|c|c|c|c|c|c|}
\hline & Baseline & $30 \mathrm{~min}$ & $120 \mathrm{~min}$ & $240 \mathrm{~min}$ & Reference range & $p$ value & Statistical test \\
\hline $\begin{array}{l}\text { White blood cells } \\
\qquad\left(\times 10^{9} / \mathrm{L}\right)\end{array}$ & $5.7( \pm 4.3 / 10.10)$ & $7.15( \pm 5.2 / 11.4)^{*}$ & $5.8( \pm 5.10 / 14.2)$ & $\begin{array}{l}8.0( \pm 3.9 \\
5.5 / 14.50)^{*}\end{array}$ & $4.0-11.0$ & 0.009 & Friedman \\
\hline Neutrophils $\left(\times 10^{9} / \mathrm{L}\right)$ & $3.6( \pm 2.4 / 7.4)$ & $4.05( \pm 2.9 / 8.60)$ & $3.8( \pm 2.90 / 11.90)$ & $5.2( \pm 3.4 / 11.2)^{*}$ & $1.7-7.5$ & 0.017 & Friedman \\
\hline $\begin{array}{l}\text { Lymphocytes } \\
\qquad\left(\times 10^{9} / \mathrm{L}\right)\end{array}$ & $1.6( \pm 1.3 / 3.6)$ & $1.85( \pm 1.3 / 3.1)$ & $1.50( \pm 1.0 / 2.2)$ & $2.0 \pm(1.0 / 3.0)$ & $1.0-4.5$ & 0.063 & Friedman \\
\hline Eosinophil $\left(\times 10^{9} / \mathrm{L}\right)$ & $0.1( \pm 0.05 / 0.4)$ & $0.1( \pm 0.02 / 0.5)$ & $0.1( \pm 0.03 / 0.2)$ & $0.1( \pm 0.03 / 0.3)$ & $0.0-0.4$ & 0.101 & Friedman \\
\hline Basophils $\left(\times 10^{9} / \mathrm{L}\right)$ & $0.025( \pm 0.01 / 0.6)$ & $0.025 \pm(0.01 / 0.6)$ & $0.02( \pm 0.01 / 0.03)$ & $0.02( \pm 0.01 / 0.07)$ & $0.0-0.1$ & 0.041 & Friedman \\
\hline Monocytes $\left(\times 10^{9} / \mathrm{L}\right)$ & $0.5( \pm 0.3 / 0.6)$ & $0.5( \pm 0.4 / 0.8)$ & $0.4( \pm 0.3 / 0.8)$ & $0.8( \pm 0.5 / 1.0)^{*}$ & $0.2-0.8$ & 0.003 & Friedman \\
\hline Haemoglobin (g/L) & $124.5( \pm 123 / 152)$ & $117.5( \pm 120 / 151)^{*}$ & $124( \pm 120 / 141)^{*}$ & $120 \pm(117 / 141)^{*}$ & $\begin{array}{l}M: 130-180 \\
F: 115-165\end{array}$ & 0.002 & Friedman \\
\hline $\begin{array}{l}\text { Red blood cells } \\
\qquad\left(\times 10^{9} / \mathrm{L}\right)\end{array}$ & $4.84( \pm 4.3 / 5.51)$ & $4.74( \pm 4.06 / 5.27)^{*}$ & $4.62( \pm 4.12 / 4.90)^{*}$ & $4.74( \pm 4.23 / 5.17)^{*}$ & $\begin{array}{l}M: 4.5-6.0 \\
F: 3.8-5.5\end{array}$ & 0.001 & Friedman \\
\hline $\begin{array}{l}\text { Mean corpuscular } \\
\text { haemoglobin (pg) }\end{array}$ & $28.83( \pm 25.4 / 31.7)$ & $29.1( \pm 26.6 / 32.4)^{*}$ & $29.4( \pm 28.7 / 32.4)^{*}$ & $29.4( \pm 27.7 / 32.1)$ & $27.0-32.0$ & 0.047 & Friedman \\
\hline Mean cell volume (fl) & $87.3( \pm 32.0 / 106.6)$ & $87.9( \pm 32.2 / 106.2)$ & $88.7( \pm 79.6 / 106.4)$ & $88.7( \pm 81.0 / 105.8)$ & $80.0-100.0$ & 0.404 & Friedman \\
\hline $\begin{array}{l}\text { Packed cell volume } \\
\quad(\mathrm{L} / \mathrm{L})\end{array}$ & $0.42 \pm 0.03$ & $0.41 \pm 0.04$ & $0.39 \pm 0.02$ & $0.41 \pm 0.03$ & $\begin{array}{l}M: 0.4-0.52 \\
F: 0.37-0.47\end{array}$ & 0.002 & ANOVA \\
\hline $\begin{array}{l}\text { Mean corpuscular } \\
\text { haemoglobin con- } \\
\text { centration }(\%)\end{array}$ & $34.02 \pm 1.65$ & $33.95 \pm 1.23$ & $34.27 \pm 1.12$ & $33.68 \pm 0.83$ & $32-36$ & 0.179 & ANOVA \\
\hline
\end{tabular}


Table 3 Biochemical changes following SWL $(n=12)$

\begin{tabular}{|c|c|c|c|c|c|c|c|}
\hline & Baseline & $30 \mathrm{~min}$ & $120 \mathrm{~min}$ & $240 \mathrm{~min}$ & Reference range & $p$ value & Statistical test \\
\hline CRP (mg/L) & $3.1( \pm 1.0 / 8.0)$ & $1.65( \pm 1.0 / 7.0)$ & $1.8( \pm 1.0 / 7.5)$ & $1.9( \pm 1.0 / 6.40)$ & $0-5.0$ & 0.101 & Friedman \\
\hline Total protein (g/L) & $71.33 \pm 4.83$ & $67.93 \pm 4.23 *$ & $64.45 \pm 3.45^{*}$ & $67.64 \pm 3.03^{*}$ & $60.0-80.0$ & $<0.001$ & ANOVA \\
\hline Albumin (g/L) & $43.13 \pm 3.0$ & $40.90 \pm 3.12^{*}$ & $39.33 \pm 3.5^{*}$ & $40.77 \pm 3.22$ & $35.0-45.0$ & $<0.001$ & ANOVA \\
\hline Globulin (g/L) & $28( \pm 25 / 37)$ & $28( \pm 22 / 30)$ & $26( \pm 23 / 27)^{*}$ & $26.5( \pm 25 / 30)$ & $23.0-35.0$ & 0.006 & Friedman \\
\hline Total bilirubin ( $\mu \mathrm{mol} / \mathrm{L})$ & $13.5( \pm 7 / 23)$ & $15( \pm 7 / 22)$ & $12( \pm 9 / 43)$ & $11( \pm 8 / 22)$ & $<21$ & 0.140 & Friedman \\
\hline $\begin{array}{l}\text { Alkaline phosphatase — ALP } \\
(\mathrm{U} / \mathrm{L})\end{array}$ & $73( \pm 36 / 91)$ & $65( \pm 37 / 93)^{*}$ & $68.5( \pm 35 / 85)^{*}$ & $72.5( \pm 34 / 86)$ & $30.0-130.0$ & 0.018 & Friedman \\
\hline $\begin{array}{l}\text { Alkaline transaminase - ALT } \\
(\mathrm{U} / \mathrm{L})\end{array}$ & $35.5( \pm 18 / 70)$ & $34( \pm 18 / 65)$ & $35( \pm 17 / 62)$ & $37( \pm 15 / 67)^{*}$ & $\begin{array}{l}<41 \text { (male) } \\
<33 \text { (female) }\end{array}$ & 0.01 & Friedman \\
\hline Urea (mmol/L) & $4.90( \pm 2.7 / 6.0)$ & $4.80( \pm 2.8 / 6.0)$ & $4.90( \pm 3.6 / 5.20)$ & $4.85( \pm 3.30 / 5.20)$ & $2.5-7.8$ & 0.478 & Friedman \\
\hline Creatinine ( $\mu \mathrm{mol} / \mathrm{L})$ & $67.1( \pm 11.39)$ & $69.7( \pm 13.04)$ & $73.0( \pm 12.30)$ & $71.1( \pm 14.09)$ & $\begin{array}{l}\text { M: } 58.0-110.0 \\
F: 46.0-92.0\end{array}$ & 0.365 & ANOVA \\
\hline Sodium (mmol/L) & $140( \pm 135 / 140)$ & $139( \pm 132 / 143)^{*}$ & $137( \pm 134 / 142)^{*}$ & $138( \pm 133 / 140)^{*}$ & $135.0-146.0$ & 0.010 & Friedman \\
\hline Potassium (mmol/L) & $4.27( \pm 3.9 / 4.6)$ & $4.37( \pm 3.64 / 4.60)$ & $4.12( \pm 3.4 / 5.0)$ & $4.2( \pm 3.8 / 4.60)$ & $3.5-5.3$ & 0.291 & Friedman \\
\hline
\end{tabular}

Statistical significance following post hoc analysis is represented when ${ }^{*} p \leq 0.05$. (M, male; $\mathrm{F}$, female)

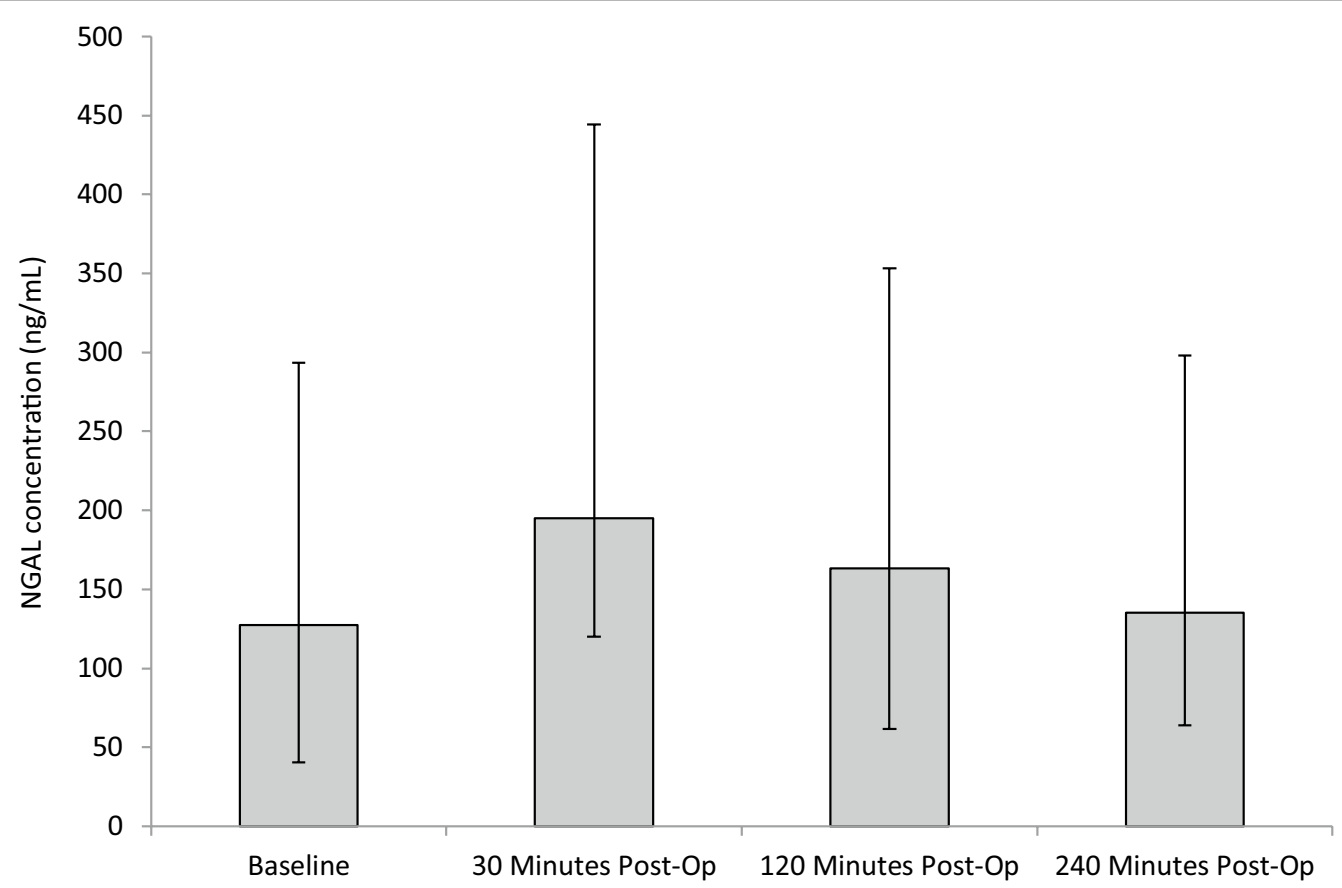

Fig. 1 The effect of SWL, for the treatment of kidney stones, on NGAL concentration. Data points expressed as median $\pm I Q R$. $p=0.033$ as determined by Friedman test. The intra-assay CV was 4.8\%. Patient samples were diluted 1 in 60 as per manufacturer guides

$(195.1 \pm 75.4 / 249.5)$ post-SWL (Fig. 1). At $120 \mathrm{~min}$ $(163.4 \pm 102.5 / 190.1)$ and $240 \mathrm{~min}(135 \pm 71.1 / 163.1)$ NGAL concentration decreased towards basal levels. According to the Friedman test, there were statistically significant rises in NGAL following SWL $(p=0.033)$. Upon further post hoc testing no other changes were observed from baseline to individual time-points $(p>0.05)$.

\section{IL-18}

Mean concentrations of plasma IL-18 increased from the baseline (pre-operatively) $(310 \pm 79.3)$ and peaked at the initial post-operative sampling of 30 min post-operatively (417.5 \pm 168.9 ) (Fig. 2). Mean concentrations of IL-18 were consistently raised with only slight changes at $120 \mathrm{~min}(378.2 \pm 160)$ and $240 \mathrm{~min}(393 \pm 181.2)$. Collectively, there was no significant difference in IL-18 


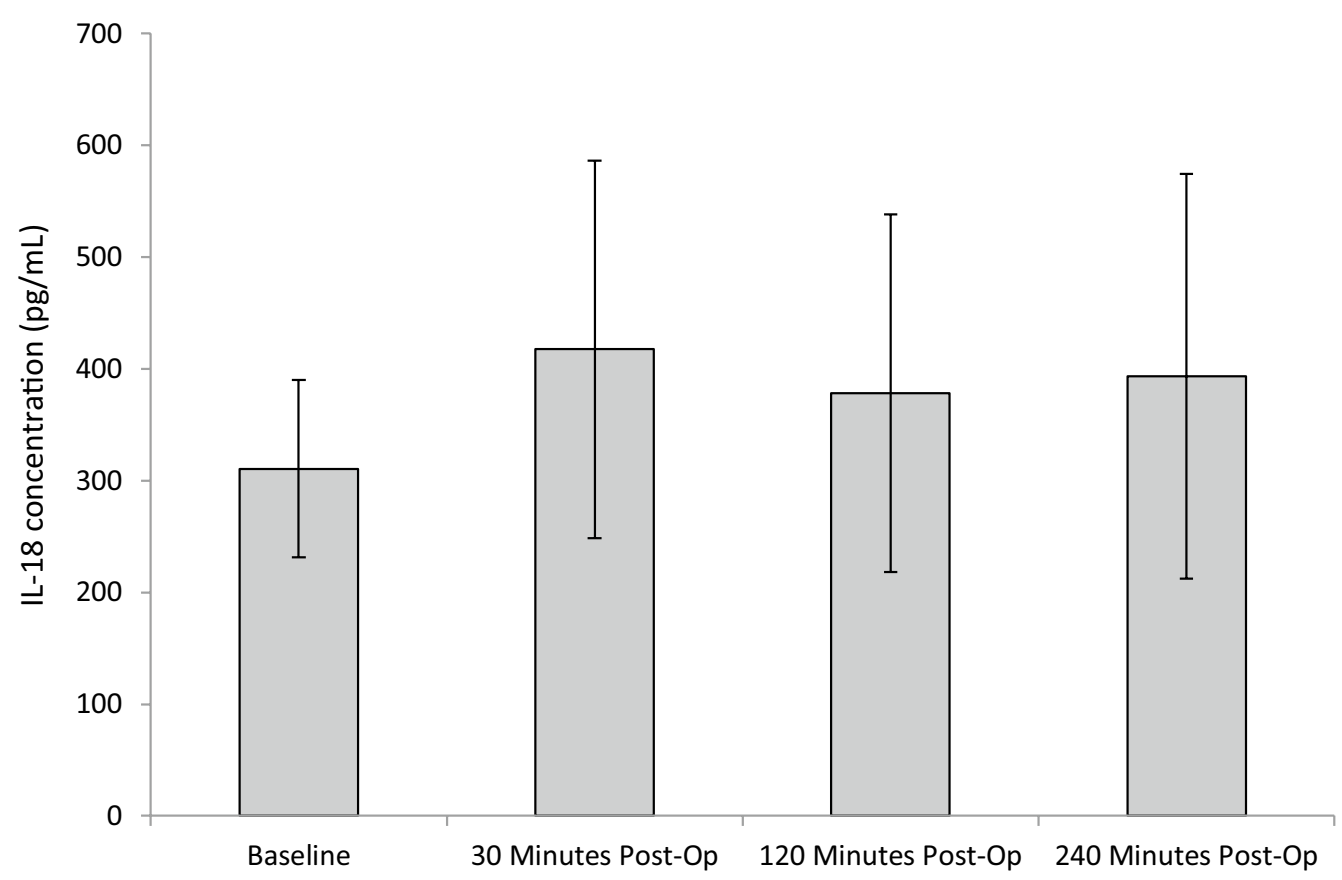

Fig. 2 The effect of SWL, for the treatment of kidney stones, on IL-18 concentration. Data points expressed as mean \pm standard deviation. $p=0.89$ as determined by a repeated measures ANOVA. The intra-assay CV was 5.1\%

$(p=0.116)$, as determined by ANOVA. Although not statistically significant, there was a trend of increasing IL-18 concentration up to $4 \mathrm{~h}$ post-SWL.

\section{IL-6}

Following SWL, IL-6 levels increased across all time-points. Specifically, IL-6 increased from baseline (pre-operative) $(2.40 \pm 1.19 / 2.47)$, during $30 \mathrm{~min}$ (3.94 $\pm 2.3 / 4.5), 120 \mathrm{~min}(6.37 \pm 4.6 / 8.8)$ and $240 \mathrm{~min}$ $(8.05 \pm 6.6 / 9.5)$ post-operatively (Fig. 3). Statistical significance was determined using the Friedman test $(p<0.01)$. Upon further testing using the Wilcoxon test a statistically significant difference was shown between the baseline value and $120 \mathrm{~min}, 240 \mathrm{~min}$ post-operatively $(p=0.013, p=0.05$, respectively).

\section{TNF- $a$}

Following SWL, TNF- $\alpha$ levels increased from baseline (pre-operative) $(1.592 \pm 0.26 / 4.75)$ and peaking at $30 \mathrm{~min}$ post-operatively $(2.18 \pm 0.67 / 2.18)$. At $120 \mathrm{~min}$ $(1.54 \pm 0.39 / 3.69)$ and $240 \mathrm{~min}(1.33 \pm 0.3 / 3.56)$ TNF- $\alpha$ concentrations decreased (Fig. 4). Statistical significance was determined using the Friedman test $(p=0.05)$. Upon further testing using the Wilcoxon test, significant difference was shown between baseline value and $30 \mathrm{~min}$ postoperatively $(p=0.041)$.

\section{IL-10}

Following SWL no significant changes were seen in IL-10 concentration, $p=0.086$ as determined by the Friedman test (Fig. 5). Although no significant changes were observed, IL-10 concentrations slightly increased from baseline $(6.43 \pm 3.7 / 7.0)$, peaking at $30 \mathrm{~min}(6.72 \pm 3.8 / 7.2)$ post-operatively. Following 120 $(4.6 \pm 2.2 / 4.7)$ and $240 \mathrm{~min}(5.65 \pm 3.5 / 6.1)$ postoperatively levels decreased.

\section{IL-8}

Following SWL, no significant changes were seen in IL-8 concentrations, $p=0.187$ as determined by the Friedman test (Fig. 6). Although non-significant, IL-8 concentrations slightly increased from baseline (13.58 $\pm 7.3 / 16.8)$ at $30 \mathrm{~min}(13.65 \pm 7.5 / 18.7)$ and decreased thereafter at $120 \mathrm{~min}(11.63 \pm 7.3 / 13.8)$, and at $240 \mathrm{~min}$ $(12.94 \pm 7.6 / 14.1)$ post-operatively.

\section{Discussion}

The aim of this study was to investigate the effects of SWL, for the treatment of kidney stones, on routine blood tests, and specific biomarkers, namely NGAL, IL-18, IL-6, IL-10 and IL-8. Interestingly, in the current study, no post-operative complications were reported. As SWL is considered a relatively minimally invasive procedure, usually undertaken under local anaesthesia, it can 


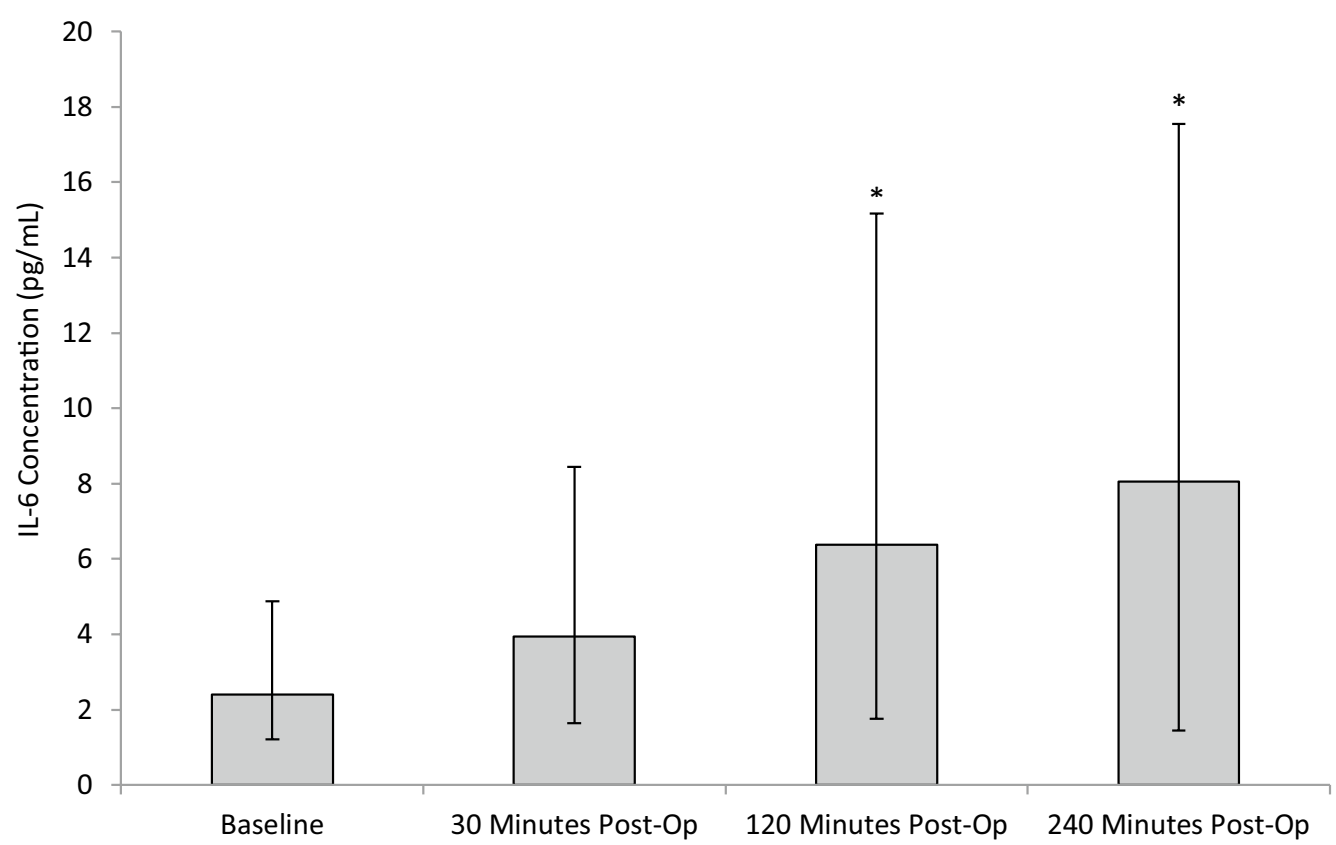

Fig. 3 The effect of SWL, for the treatment of kidney stones, on IL-6 concentration. Data points expressed as median \pm IQR. $p<0.001$ as determined by Friedman test. The intra-assay CV was $8.1 \%$

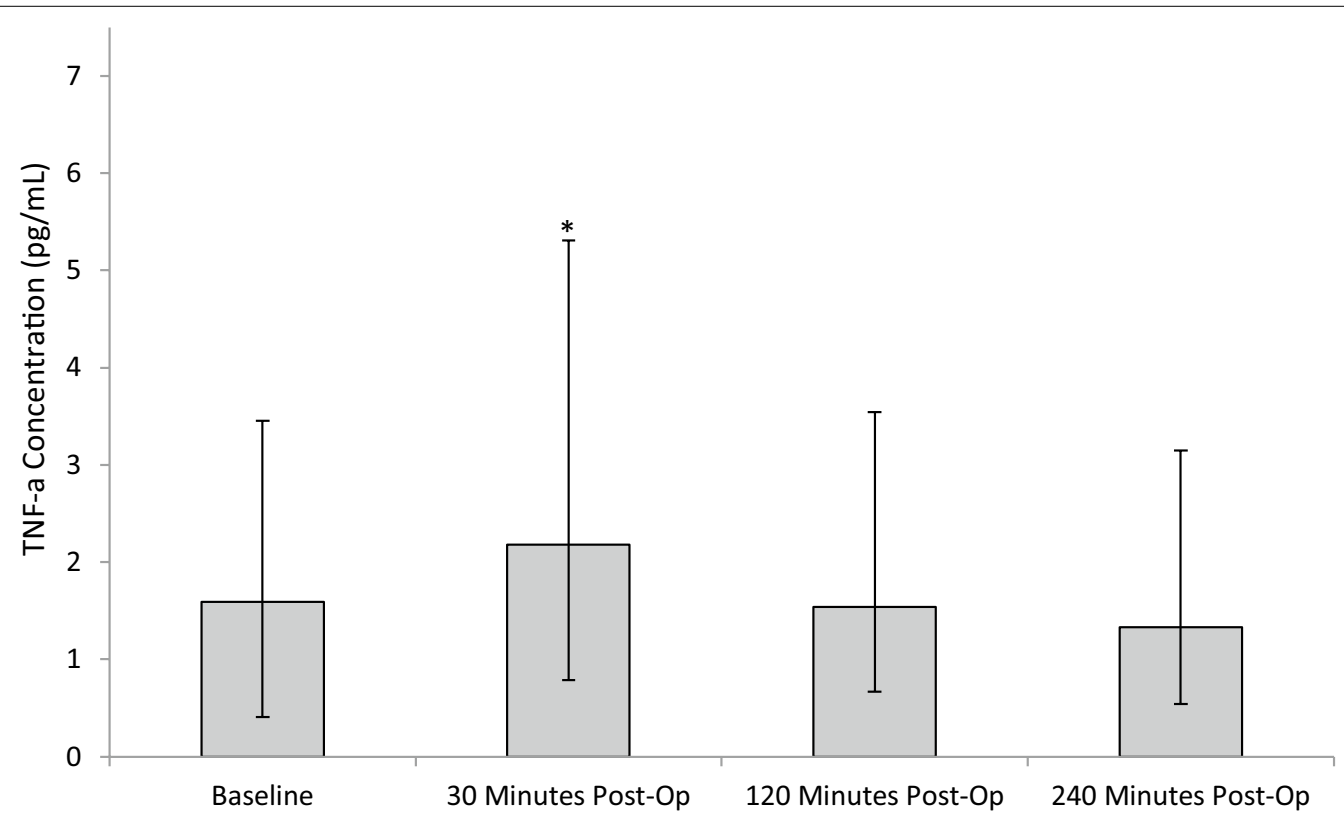

Fig. 4 The effect of SWL, for the treatment of kidney stones, on TNF-a concentration. Data points expressed as median $\pm I Q R r . p=0.05$ as determined by Friedman test. The intra-assay CV was 6.5\%

be appreciated that the reported outcomes are directly relatable to the procedure. It can therefore be appreciated that this prospective feasibility study provides crucially important information on "normal" physiological outcomes after SWL.

With regard to routine blood tests, significant changes to several haematological and biochemical 


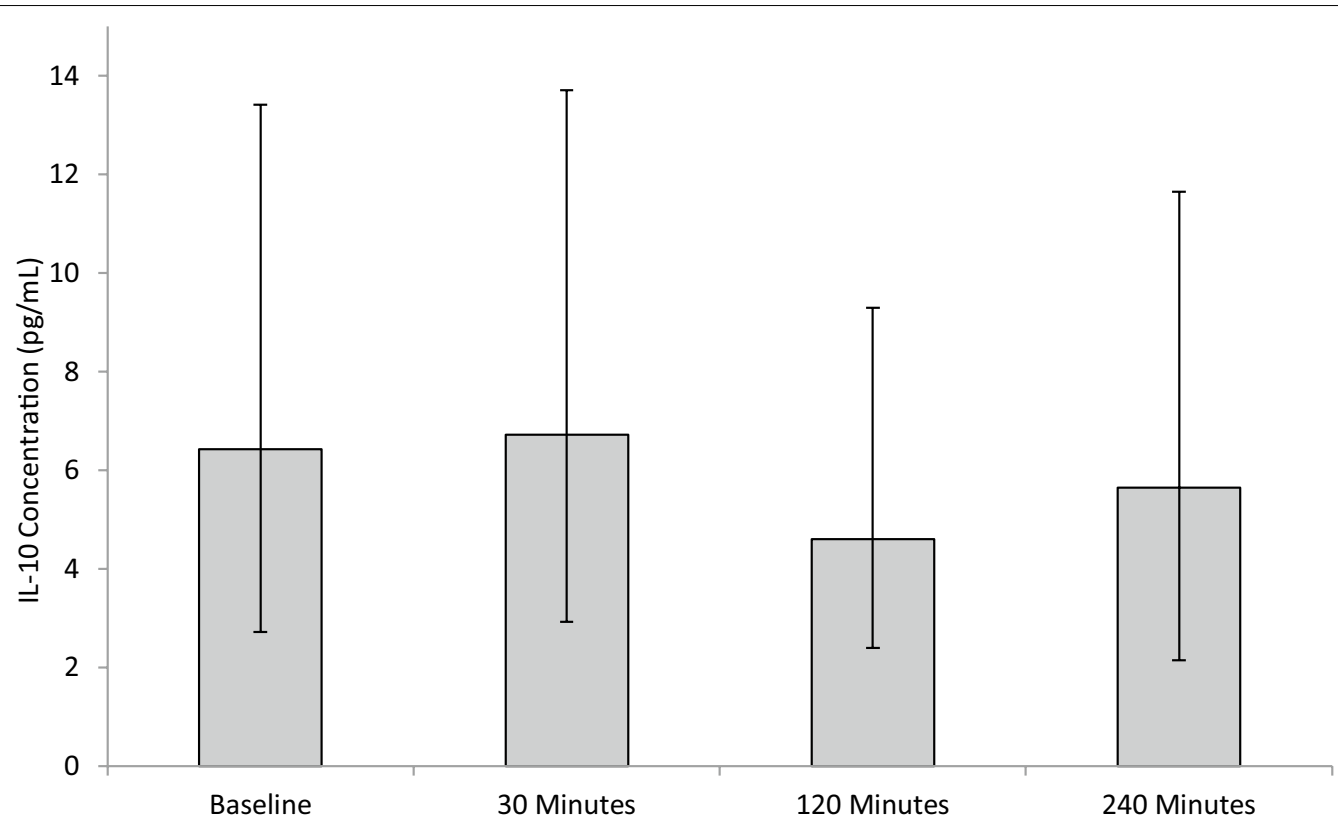

Fig. 5 The effect of SWL, for the treatment of kidney stones, on IL-10 concentration. Data points expressed as median $\pm I Q R r . p=0.086$ as determined by Friedman test. The intra-assay CV was $8.1 \%$

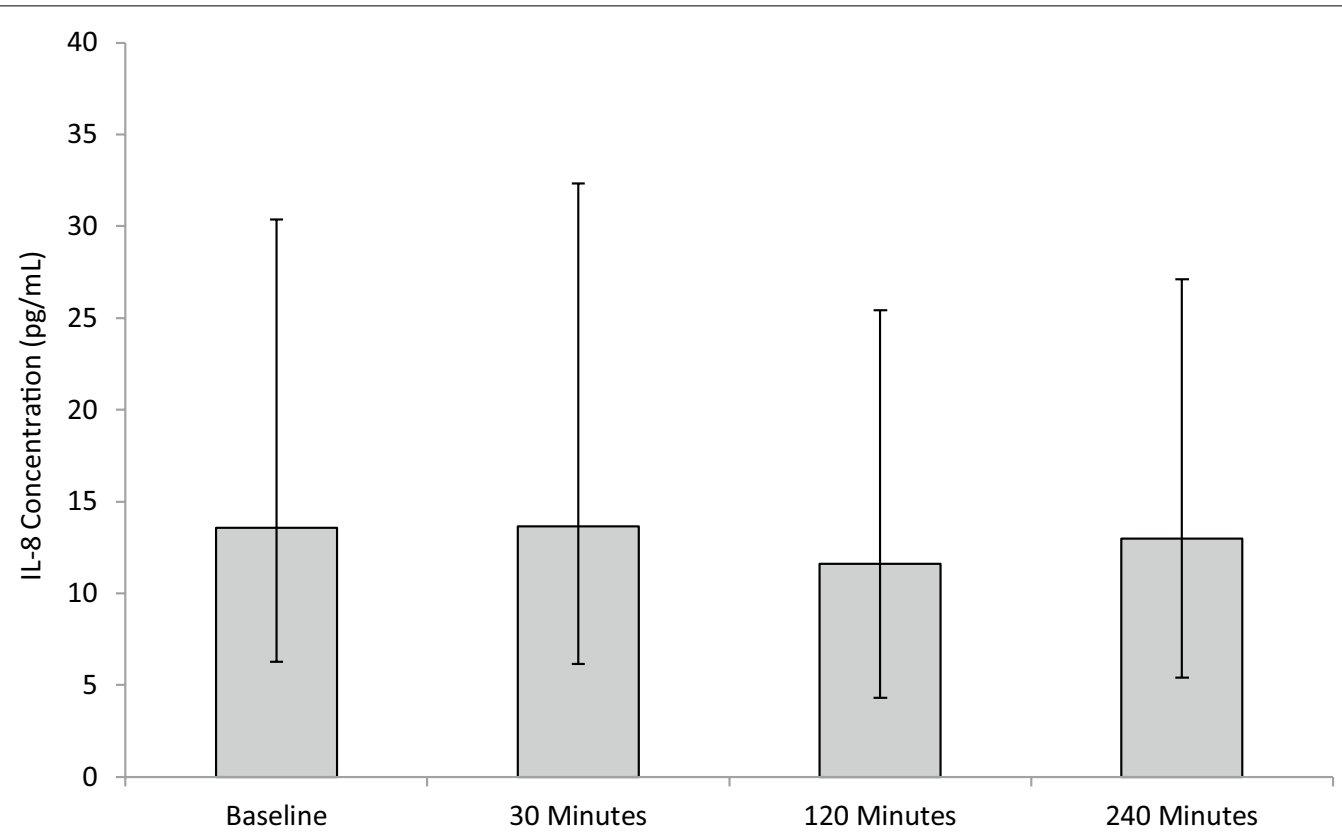

Fig. 6 The effect of SWL, for the treatment of kidney stones, on IL-8 concentration. Data points expressed as median $\pm I Q R r . p=0.187$ as determined by Friedman test. The intra-assay CV was 5.1\%

parameters were observed following SWL. Interestingly, our findings are like those occurring after other minimally invasive urological surgery for the treatment of kidney stones [19]. In the present study, specifically, total leukocyte (white blood cells), neutrophils, erythrocytes (red blood cells) and haemoglobin concentrations, increased and decreased, respectively; whilst significant decreases in total protein, albumin, globulin, ALP, and sodium (biochemical parameters) were observed. 
Changes to haematological markers following upper and lower limb orthopaedic surgical procedures have been reported by others $[16,17]$. However, little is known about the role of routine biochemical and haematological blood tests following SWL. Hughes et al. [15] have previously reported changes to fibrinogen and vWF (haemostatic function markers), that may help identify and subsequently predict patients at increased risk of bleeding complications following SWL. Similar observations were reported by Wozniak et al. [18], where it was proposed that oxidative stress may result in haemostatic changes in kidney stone patients, both prior to and especially after SWL, suggesting that SWL modulates haemostasis, and may contribute to coagulopathy episodes that can occur in high-risk patients following SWL.

In addition to the routine blood test results, biomarkers such as NGAL, IL- 6 and TNF- $\alpha$ significantly increased following SWL, with the most noticeable changes occurring at $30 \mathrm{~min}$ post-operatively for most biomarkers. Devarajan [21] has reported that NGAL provides an excellent biomarker for the early diagnosis of AKI, and for the prediction of clinical outcomes and mortality in several common clinical circumstances. Biologically, it can be appreciated that during SWL, high stresses are placed on the kidney, which may result in AKI, and subsequent impairment of renal function. Serum creatinine has long been considered a biomarker of choice for AKI, although not sensitive and is unreliable. With regard to our present study, creatinine levels increased beyond $2 \mathrm{~h}$ post-SWL, whereas NGAL peaked at $30 \mathrm{~min}$ and returned towards basal levels between 2 and $4 \mathrm{~h}$. It may therefore be proposed that any sustained increased changes to NGAL may provide a reliable marker for identifying and subsequently monitoring AKI following SWL.

Although there are many variables that can influence NGAL concentration within blood, such as GFR and formation of the biological agent by other cells such as neutrophils, it is important to remember that NGAL is not specific in diagnosing the aetiology of renal impairment, but may apply a crude method of indicating some sort of underlying pathology that needs to be clinically addressed [21, 34, 35]. It could therefore be appreciated that NGAL could act as an indicator, upon which further investigations, including medical imaging, analysis of a panel of biomarkers are undertaken to reveal the full extent of the complications.

With regard to IL-18, Faust et al. [25] and Parikh et al. [26] demonstrated that this pro-inflammatory cytokine is expressed in renal tubular epithelial cells, and urine levels of IL-18 have been reported to be raised in AKI compared to those with other co-morbidities, such as urinary tract infection. Although no significant changes were observed in IL-18 concentration following SWL in the present study, trends of increasing levels were reported, highlighting the need to undertake further studies involving larger cohorts into this novel biological parameter.

Previous studies have reported of raised serum IL-6 levels being associated with sepsis in AKI patients [23, 24]. Our study reports a similar pattern of increasing IL-6 following SWL. Although one can appreciate that further investigations involving a larger cohort would be required, IL-6 may potentially provide an additional biomarker screening tool for predicting the severity of AKI and subsequent urosepsis that may develop in highrisk patients following lithotripsy. A similar pattern of increasing TNF- $\alpha$ concentration was observed following SWL, which affirms along with other studies the integral role that this cytokine plays during an inflammatory response $[27,28]$. Although no significant changes were observed in IL-10 and IL-8, trends of increasing concentrations were observed in the present study. These findings agree with others who have demonstrated increased levels in various clinical settings $[30,32,36]$.

To date, little is known about the effect of SWL on routine blood tests and novel biomarkers. This pilot-study, we believe, has contributed to the literature, as well as providing the biological basis for future multi-centre studies. We have shown that changes to several biochemical and haematological (routine) blood tests, including specific biomarkers, such as NGAL, occur following SWL. It is hypothesised that if larger multi-centre cohort studies reproduce these findings, then these biomarkers (or probably a panel of biomarkers) may potentially provide clinicians with a better understanding of the "normal" physiological response following SWL, and thus may allow changes in clinical protocols for patient management. For example, any sustained changes to selective biomarkers, may provide clinically useful information, such as identifying or predicting the development of infection or significant bleeding episodes following SWL [13, 15-17].

Clearly, the weaknesses of this study include patient numbers which have been recruited thus far $(n=12)$, subsequent blood sampling opportunities beyond $4 \mathrm{~h}$, and the use of controls. Although the numbers are small, it was designed as a pilot study, and as such, we feel that we have provided a scientific basis to assess these biomarkers and their correlation with clinical outcome, in a larger multi-centre cohort study. Logistically, it was very difficult to retain patients beyond $4 \mathrm{~h}$, as SWL was carried out as a strict day case treatment. Our current ethical approval did not allow SWL to be performed with normal healthy individuals (e.g. control patients, without kidney stones), but in future studies we could compare SWL with kidney stone patients undergoing other minimally invasive therapies. This 
approach could also allow us to identify and establish the "normal" post-operative physiological response after urological treatment.

\section{Conclusion}

Changes to routine blood tests and specific biomarkers, in the future, may be more useful for clinicians. In turn, identification of a panel of biomarkers could provide valuable data on "normal" physiological response after lithotripsy. Ultimately, studies could be expanded to identify or predict those patients at increased risk of developing post-operative complications, such as acute kidney injury or. These studies, however, need validating involving larger cohorts.

\section{Abbreviations}

AKI: Acute kidney injury; EDTA: Ethylene diaminetetraacetic acid; NGAL: Neutrophil gelatinase-associated lipocalin; ESR: Erythrocyte sedimentation rate; IL: Interleukin; TNF-a: Tumour necrosis factor-alpha; SD: Standard deviation; SWL: Shock wave lithotripsy.

\section{Acknowledgements}

The authors are indebted to the patients who kindly agreed to take part in this study.

\section{Authors' contributions}

Conceived concept, study designed and supervision: SFH and IS. Performed the experiments: NJ, AJM, JB and SJTW. Analysed and interpreted the data: NJ, SJTW, JB, SFH. Wrote the paper: SFH, NJ and IS. All authors read and approved the final manuscript.

\section{Funding}

The authors thankfully acknowledge the Institute of Biomedical Science (IBMS) for their financial support.

\section{Availability of data and materials}

All data generated or analysed during this study are included in the published article.

\section{Ethics approval and consent to participate}

Written informed consent was obtained from patients under a protocol approved by the Welsh Research Ethics Service (REC) 4 committee (REC4: 12/ WA/0117).

\section{Consent for publication}

Not applicable.

\section{Competing interests}

The authors declare that they have no competing interests.

\section{Author details}

${ }^{1}$ North Wales Clinical Research Centre, Betsi Cadwaladr University Health Board (BCUHB) Wrexham Maelor Hospital, Wrexham, Wales, UK. ${ }^{2}$ North Wales \& North West Urological Research Centre, Betsi Cadwaladr University Health Board (BCUHB) Wrexham Maelor Hospital, Wrexham, Wales, UK. ${ }^{3}$ Department of Biological Sciences, University of Chester, Chester, UK. ${ }^{4}$ Department of Haematology, Countess of Chester Hospital, Chester, UK. ${ }^{5}$ Department of Blood Sciences, BCUHB Wrexham Maelor Hospital, Wrexham, Wales, UK. ${ }^{6}$ School of Medical Sciences, Bangor University, Bangor, Wales, UK. ${ }^{7}$ The Alan de Bolla Department of Urology, BCUHB Wrexham Maelor Hospital, Wrexham, Wales, UK.
Received: 21 April 2020 Accepted: 27 May 2020

Published online: 01 June 2020

\section{References}

1. Romero V, Akpinar H, Assimos DG. Kidney stones: a global picture of prevalence, incidence, and associated risk factors. Rev Urol. 2010;12(2-3):e86-96.

2. Lee YJ, Oh SN, Rha SE, Byun JY. Renal trauma. Radiol Clin N Am. 2007; 45(3): 581-592, ix. https://doi.org/10.1016/j.rcl.2007.04.004.

3. Turney BW, Reynard JM, Noble JG, Keoghane SR. Trends in urological stone disease. BJU Int. 2012;109(7):1082-7. https://doi.org/10.1111/ j.1464-410X.2011.10495.x

4. Chaussy C, Schmiedt E, Jocham D, Brendel W, Forssmann B, Walther V. First clinical experience with extracorporeally induced destruction of kidney stones by shock waves. J Urol. 1981;167(5):1957-60.

5. McAteer JA, Evan AP. The acute and long-term adverse effects of shock wave lithotripsy. Semin Nephrol. 2008;28(2):200-13. https://doi. org/10.1016/j.semnephrol.2008.01.003.

6. Baumgartner BR, Dickey KW, Ambrose SS, Walton KN, Nelson RC, Bernardino ME. Kidney changes after extracorporeal shock wave lithotripsy: appearance on MR imaging. Radiology. 1987;163(2):531-4. https://doi. org/10.1148/radiology.163.2.3562837.

7. Shao Y, Connors BA, Evan AP, Willis LR, Lifshitz DA, Lingeman JE. Morphological changes induced in the pig kidney by extracorporeal shock wave lithotripsy: nephron injury. Anat Rec A Discov Mol Cell Evol Biol. 2003;275(1):979-89. https://doi.org/10.1002/ar.a.10115.

8. Newman R, Hackett R, Senior D, Brock K, Feldman J, Sosnowski J, Finlayson B. Pathologic effects of ESWL on canine renal tissue. Urology. 1987:29(2):194-200.

9. Cornu JN, Herrmann T, Traxer O, Matlaga B. Prevention and management following complications from endourology procedures. Eur Urol Focus. 2016;2:49-59.

10. Skolarikos A, Gross A, Krebs A, Unal D, Bercowsky E, Eltahawy E, et al. Outcomes of flexible ureterorenoscopy for solitary renal stones in the CROES URS global study. J Urol. 2015;194:37-143.

11. Hassan I, Zietlow SP. Acute pancreatitis after extracorporeal shock wave lithotripsy for a renal calculus. Urology. 2002;60:1111.

12. Rashid P, Steele D, Hunt J. Splenic rupture after extracorporeal shock wave lithotripsy. J Urol. 1996;156:1756-7.

13. Mobley TB, Myers DA, Grine WB, et al. Low energy lithotripsy with the Lithostar: treatment results with 19,962 renal and ureteral calculi. J Urol. 1993:149:1419-24.

14. Patel KL, Gross J. Extracorporeal shock wave lithotripsy induced abdominal aortic aneurysm rupture. J Am Geriatr Soc. 1991;39:318-9.

15. Hughes SF, Thomas-Wright SJ, Banwell J, Williams R, Moyes AJ, Mushtaq S, Shergill I. A pilot study to evaluate haemostatic function, following shock wave lithotripsy (SWL) for the treatment of solitary kidney stones. PLoS ONE. 2015;10(5):e0125840. https://doi.org/10.1371/journal.pone.0125840.

16. Hughes SF, Hendricks BD, Edwards DR, Middleton JF. Tourniquet-applied upper limb orthopaedic surgery results in increased inflammation and changes to leukocyte, coagulation and endothelial markers. PLOS ONE. 2010;5(7):e1 1846. https://doi.org/10.1371/journal.pone.0011846.

17. Hughes SF, Hendricks BD, Edwards DR, Bastawrous SS, Middleton JF. Lower limb orthopaedic surgery results in changes to coagulation and non-specific inflammatory biomarkers, including selective clinical outcome measures. Eur J Med Res. 2013;18:40. https://doi. org/10.1186/2047-783x-18-40.

18. Woźniak P, Kontek B, Różański W, Olas B. Evaluation of hemostasis parameters and the role of the oxidative damage to plasma proteins in the modulation of hemostasis in patients with nephrolithiasis before and after extracorporeal shock wave lithotripsy. PLOS ONE. 2017;12(10):e0185157. https://doi.org/10.1371/journal.pone.0185157.

19. Moyes AJ, Lamb RM, Ella-Tongwiis P, Pushkaran A, Ahmed I, Shergill I, Hughes SF. A pilot study evaluating changes to haematological and biochemical tests after flexible ureterorenoscopy for the treatment of kidney stones. PLoS ONE. 2017;12(7):e0179599. https://doi.org/10.1371/ journal.pone.0179599.

20. Mishra J, Mori K, Ma Q, Kelly C, Yang J, Mitsnefes M, Devarajan P. Amelioration of ischemic acute renal injury by neutrophil 
gelatinase-associated lipocalin. J Am Soc Nephrol. 2004;15(12):3073-82. https://doi.org/10.1097/01.ASN.0000145013.44578.45.

21. Devarajan P. Review: neutrophil gelatinase-associated lipocalin: a troponin-like biomarker for human acute kidney injury. Nephrology. 2010;15(4):419-28. https://doi.org/10.1111/j.1440-1797.2010.01317.x.

22. Chakraborty S, Kaur S, Guha S, Batra SK. The multifaceted roles of neutrophil gelatinase associated lipocalin (NGAL) in inflammation and cancer. Biochim Biophys Acta. 2012;1826(1):129-69. https://doi.org/10.1016/j. bbcan.2012.03.008.

23. Chawla LS, Seneff MG, Nelson DR, Williams M, Levy H, Kimmel PL, Macias WL. Elevated plasma concentrations of IL-6 and elevated APACHE 2 score predict acute kidney injury in patients with severe sepsis. CJASN. 2007:2(1):22-30.

24. Kowen O, Molitoris BA, Pescovitz M, Kelly KJ. Urinary actin, interleukin-6, and interleukin-8 may predict sustained ARF after ischemic injury in renal allografts. Am J Kidney Dis. 2003:41:1074-87.

25. Faust J, Menke J, Kriegsmann J, Kelley VR, Mayet WJ, Galle PR, Schwarting A. Correlation of renal tubular epithelial cell-derived interleukin-18 up-regulation with disease activity in MRL-Fas/pr mice with autoimmune lupus nephritis. Arthritis Rheum. 2002;46(11):3083-95. https://doi. org/10.1002/art.10563.

26. Parikh CR, Mishra J, Thiessen-Philbrook H, Dursun B, Ma Q, Kelly C, Edelstein CL. Urinary IL-18 is an early predictive biomarker of acute kidney injury after cardiac surgery. Kidney Int. 2006;70(1):199-203. https://doi. org/10.1038/sj.ki.5001527.

27. Chandrasekharan UM, Siemionow M, Unsal M, Yang L, Poptic E, Bohn J, Ozer K, Zhou Z, Howe PH, Penn M, DiCorleto P. Tumour necrosis factor a receptor 2 is required for TNF- $a$-induced leukocyte-endothelial interaction in vivo. Blood. 2007;109(5):1938-44.

28. Lauterbach M, O'Donnell P, Asano K, Mayadas TN. Role of TNF priming and adhesion molecules in neutrophil recruitment to intravascular immune complexes. JLB. 2008;83(6):1423-30.
29. Shahzad A, Knapp M, Lang I, Kohler G. Interleukin-8 (IL-8)—a universal biomarker? Int Arch Med. 2010;3:11.

30. Duan ZG, Yang WM. Analysis of cytokines (IL-2, IL-8, IL-10) in the expressed prostatic secretions of chronic prostatitis. Zhanghua Non Ke Xug. 2005;11(3):201-3.

31. Rao WH, Evans GS, Finn A. The significance of interleukin 8 in urine. Arch Dis Child. 2001:85:256-62

32. Rabinovich A, Medina L, Piura B, Huleihel M. Expression of IL-10 in human normal and cancerous ovarian tissue cells. Eur Cytokine Netw. 2010;21(2):122-8

33. Sabat R, Grutz G, Warszawska K, Kirsch S, Witte E, Wolk K, Geginat. Biology of interleukin-10. Cytokine Growth Factor Rev. 2010;21:331-44.

34. Hall IE, Yarlagadda SG, Coca SG, Wang Z, Doshi M, Devarajan P, Parikh CR. IL-18 and urinary NGAL predict dialysis and graft recovery after kidney transplantation. J Am Soc Nephrol. 2010;21(1):189-97. https://doi. org/10.1681/ASN.2009030264

35. Kardakos IS, Volanis DI, Kalikaki A, Tzortzis VP, Serafetinides EN, Melekos MD, Delakas DS. Evaluation of neutrophil gelatinase-associated lipocalin, interleukin-18, and cystatin c as molecular markers before and after unilateral shock wave lithotripsy. Urology. 2014. https://doi.org/10.1016/j. urology.2014.05.034.

36. Fitzgerald DC, Zhang GX, El-Behi M, Fonseca-Kelly Z, Li H, Yu S. Suppression of autoimmune inflammation of the central nervous system by interleukin 10 secreted by interleukin 27-stimulated T-cells. Nat Immunol. 2007:8:1372-9.

\section{Publisher's Note}

Springer Nature remains neutral with regard to jurisdictional claims in published maps and institutional affiliations.
Ready to submit your research? Choose BMC and benefit from:

- fast, convenient online submission

- thorough peer review by experienced researchers in your field

- rapid publication on acceptance

- support for research data, including large and complex data types

- gold Open Access which fosters wider collaboration and increased citations

- maximum visibility for your research: over $100 \mathrm{M}$ website views per year

At BMC, research is always in progress.

Learn more biomedcentral.com/submissions 